\title{
Bioactive glass suspensions preparation for suspension plasma
}

\section{spraying}

\author{
E. Cañas ${ }^{(a, *)}$, M. Vicent ${ }^{(a)}$, M.J. Orts ${ }^{(a)}$, R. Moreno ${ }^{(b)}$, E. Sánchez ${ }^{(a)}$
}

a) Instituto de Tecnología Cerámica (ITC), Asociación de Investigación de las Industrias Cerámicas (AICE), Universitat Jaume I, 12006, Castellón, Spain

b) Instituto de Cerámica y Vidrio (ICV), Consejo Superior de Investigaciones Científicas (CSIC), Universidad Autónoma de Madrid, 28049, Madrid, Spain

Eugeni Cañas Recacha

Telephone number: (+34) 964342424

Email: eugeni.canas@itc.uji.es

Fax number: (+34) 964342425

Mónica Vicent Cabedo

Email: monica.vicent@itc.uji.es

María José Orts Tarí

Email: mariajose.orts@itc.uji.es

Rodrigo Moreno Botella

Email: rmoreno@icv.csic.es

Enrique Sánchez Vilches

Email: enrique.sanchez@itc.uji.es 


\section{Abstract}

A bioactive glass was dry-milled and sieved in order to obtain powders with particle size finer than $63 \mu \mathrm{m}$. Two suspensions, with different particle size distribution $\left(\mathrm{D}_{50}=\right.$ $8.3 \mu \mathrm{m}$ and $\mathrm{D}_{50}=2.2 \mu \mathrm{m}$ ), were subsequently obtained from milling those powders in an organic solvent (dipropylene glycol methyl ether) by using two different grinding steps. The obtained suspensions were characterised and stabilised to produce adequate feedstocks to be used in suspension plasma spraying technique. For that purpose, sedimentation tests as well as rheological characterisation were carried out on both suspensions.

Only the suspension feedstock containing the finest particle size, managed to produce a coating with suitable thickness and adherence on the substrate when a $\mathrm{TiO}_{2}$ bond coat was used. Besides X-ray diffraction findings confirmed the amorphous nature of the obtained coatings. However coating microstructure displayed many round, closed pores and surface observation revealed the presence of abundant non-deformed splats.

Keywords: Bioactive glass suspension; Rheology; Sedimentation; Suspension plasma spraying; Bioactive glass coating

\section{Introduction}

Nowadays, it is very usual to employ bioceramic materials to heal or replace damaged areas of the body, since these materials have an excellent biocompatibility with human body. Nevertheless, they are brittle materials with poor mechanical properties, therefore, their use in load-bearing applications is limited [1-5]. This constraint can largely be overcome by depositing these materials onto metallic implants, obtaining a composite that combines good mechanical and biological properties [6]. There are several methods to deposit these materials, but the most common one is atmospheric plasma spraying (APS) due to its feasibility and the good bond between the coating and the substrate [7$10]$.

Crystalline calcium phosphate, like hydroxyapatite (HA), is the most employed bioceramic material to obtain bioactive coatings by APS, due to its similar composition to that of bones. Nevertheless, HA coatings require crystalline feedstocks of high purity, which increases the cost of the final product. Furthermore, during deposition by APS, 
HA tends to decompose partially resulting in coatings with a mixture of amorphous and crystalline zones, leading to a reduction of their bioactivity. Hence, to overcome this drawback in the development of biological coatings by APS, HA could be replaced by bioactive glasses (BGs), amorphous bioceramic materials which are prepared from a mixture of oxides such as $\mathrm{SiO}_{2}, \mathrm{CaO}, \mathrm{Na}_{2} \mathrm{O}, \mathrm{K}_{2} \mathrm{O}, \mathrm{MgO}$ and $\mathrm{P}_{2} \mathrm{O}_{5}$. The fabrication of sintered bioactive glasses is complex due to their tendency to crystallise during sintering [11]. However, these materials could be obtained by two well-known techniques, namely the sol-gel method or the fusion and crushing procedure, i.e. the melting and subsequent quenching to obtain the glass powder $[12,13]$. Although HA and BG show good biocompatibility and have similar mechanical properties [1], bioactive glasses display higher bioactivity, resulting in less reaction time within the coating and the host tissue, and greater bonding between them [1,2]. Moreover, during the deposition by APS, bioactive glasses preserve their amorphous feature, which is necessary to obtain the desirable bioactivity of the BG coatings as reported in the literature [14-16].

In the last few years, there has been a growing interest in the use of suspensions instead of powders as feedstock for plasma spraying. The liquid feedstock is fed into the plasma torch by injection or atomisation. This new technique is called suspension plasma spraying (SPS), and represents a solution to obtain fine microstructured coatings without handling very fine powders (with particle size lower than 5-10 $\mu \mathrm{m}$ ) which exhibit poor flowability to be plasma-sprayed [17]. Thus, the incorporation of these fine powders into stable suspensions that are subsequently fed into the plasma represents a feasible and interesting solution. Not less important, the use of a suspension instead of powder as a feedstock entails significant cost savings due to the simplification of the feedstock preparation as well as the elimination of possible post-spray treatments [18]. Liquid feedstocks must exhibit very low viscosity to be injected into the plasma plume, as well as good physical and chemical stability, to evade the formation of agglomerates that can block the injector and impede a homogenous heating of the particles [19].

The SPS feedstocks could be prepared in both aqueous and organic medium, but not all organics are suitable for thermal spraying. The organic medium employed must accomplish some requirements such as adequate flash point or explosive limits in order to avoid accidents during spraying. Water and ethanol are the most employed liquids in SPS feedstocks preparation, each one showing advantages and disadvantages. When aqueous feedstock is employed, safer handling and storage are achieved but water vaporisation tends to cool the plasma plume, reducing the melting degree of the flying 
particles. On the other hand, when ethanol evaporates, an increment of the plasma plume temperature takes place, and consequently, the heat transmitted to the particles enhances particle melting. Nevertheless, employing an organic liquid makes it more dangerous the handling and storage in comparison with water, as mentioned above [19]. In the case of bioactive glass coatings obtained by SPS, the BG suspensions have to be prepared employing an organic medium instead of water, due to the chemical reaction (leaching) that occurs between the BG particles and water, which leads to a modification of the glass structure resulting in the gelling of the suspension [20].

Regardless the solvent used, BG feedstocks must be sufficiently stable for the suitable suspension conveying and spraying to occur. Stability means that particles in the suspensions must be well dispersed with little or no agglomeration trend during deposition. In fact, agglomerates can clog the nozzle hole as well as settle during suspension feeding giving rise to an inefficient or inadequate SPS process.

SPS of BG suspensions represents a very incipient research line in thermal spray literature. For this reason, very few papers on this topic are reported. In these papers, the preparation of the suspension feedstock does neither focus on the choice of a solvent (usually ethanol) nor on the solids content necessary for the SPS process to occur [2123]. However, details about the colloidal or rheological behaviour of the suspension or time-stability (sedimentation trend) data of the SPS feedstock are rarely provided.

Consequently, the aim of the present work is to study and characterise the preparation process to produce stable bioactive glass suspensions from a BG powder. The final objective is to obtain suitable non-aqueous suspension feedstocks for the SPS process. The working plan comprises two wet milling steps, since it is very difficult to reduce the particle size down to a few microns in just one step, employing an organic liquid as a milling and suspension medium. The organic solvent (dipropylene glycol methyl ether) was previously selected to accomplish with technical and safety requirements of the process. Both suspensions, obtained from each milling step, were rheologically characterised and sedimentation tests were also performed to determine their stability with time. Different dispersants were also tested to provide the desired suspension stabilisation.

Finally, both suspensions were sprayed on metallic substrates by SPS with the aim of knowing if they were suitable as feedstocks to obtain coatings, whose microstructure was examined by field-emission environmental scanning electron microscopy (FEG- 
ESEM) and their amorphous or crystalline feature was determined by X-ray diffraction (XRD).

\section{Experimental}

\subsection{Feedstocks preparation and characterisation}

In the present work, a bioactive glass with a composition of $47.6 \mathrm{SiO}_{2}, 5.3 \mathrm{P}_{2} \mathrm{O}_{5}, 23.1$ $\mathrm{CaO}$ and $24.0 \mathrm{Na}_{2} \mathrm{O}$ (in oxide wt $\%$ ) was obtained by melting and quenching, as previously reported [24]. Then, the glass was dry milled in a hammer mill and sieved to obtain a powder with a particle size lower than $63 \mu \mathrm{m}$. The obtained powder was mixed with an organic liquid maintaining the solids content as 10 vol.\%. Dipropylene glycol methyl ether (Dowanol DPM, Dow Chemical, USA) was employed as organic suspension medium, since this environmental sound solvent provides good results as suspension medium when it is employed to prepare ceramic inks for digital printing. In table 1, are summarised the main characteristics of this medium in comparison with ethanol, a solvent commonly used in SPS process. It can be appreciated that the physical properties of both solvents (viscosity and surface tension) are quite similar, but Dowanol DPM has higher flash point than ethanol making handle, storage and transport of Dowanol suspensions safer and easier. On the other hand, the evaporation rate of Dowanol is lower than that of ethanol (higher vapour pressure and enthalpy of vaporisation). However, this constraint could be solved by increasing the solids content, resulting in a reduction of the amount of solvent to evaporate.

Table 1 Main properties of the organic medium employed compared with ethanol (obtained by suppliers)

\begin{tabular}{cccccccc}
\hline Solvent & $\mathbf{M}_{\mathbf{w}}{ }^{\mathrm{a}}$ & $\boldsymbol{\rho}^{\mathrm{b}}$ & $\boldsymbol{\mu}^{\mathrm{c}}$ & $\boldsymbol{\gamma}^{\mathrm{d}}$ & $\mathbf{P}_{\mathbf{v}}{ }^{\mathrm{e}}$ & $\boldsymbol{\Delta} \mathbf{H}_{\mathbf{v}}$ & $\mathbf{T}^{\mathrm{g}}$ \\
\hline Dowanol & 148.2 & 948 & 3.7 & 28.8 & 0.3 & 0.65 & 348 \\
\hline Ethanol & 46.1 & 790 & 1.2 & 25.1 & 59 & 0.93 & 293 \\
\hline
\end{tabular}

\footnotetext{
${ }^{a}$ Molecular weight $\left(\mathrm{kg} \mathrm{kmol}^{-1}\right)$

${ }^{\mathrm{b}}$ Density $\left(\mathrm{kg} \mathrm{m}^{-3}\right)$ measured at $298 \mathrm{~K}$

${ }^{c}$ Viscosity (Pa s) $10^{3}$ measured at $298 \mathrm{~K}$

${ }^{\mathrm{d}}$ Surface Tension $\left(\mathrm{N} \mathrm{m}^{-1}\right) \cdot 10^{3}$ measured at $298 \mathrm{~K}$

${ }^{\mathrm{e}}$ Vapour Pressure ( $\mathrm{mm} \mathrm{Hg}$ ) measured at $293 \mathrm{~K}$

${ }^{\mathrm{f}}$ Enthalpy of vaporisation $\left(\mathrm{J} \mathrm{kg}^{-1}\right) \cdot 10^{-6}$

${ }^{\mathrm{g}}$ Flash Point $(\mathrm{K})$
} 
The resulting mixture was wet milled in a planetary mill (Pulverisette 5, Fritsch GmbH, Germany) with alumina balls, to obtain a bioactive glass suspension (referred to as BGPul). The optimum milling time to achieve the finest particle size in the first milling step was determined by sedimentation in a test tube. For that purpose, various tests were carried out for different times, measuring for each time the volume of suspended solids in the test tube after one hour. When this volume remains constant, it means that finer particle size cannot be achieved with longer milling time. Moreover, density of the obtained suspension was determined by pycnometer, and the particle size distribution was measured by laser diffraction (Mastersizer 2000, Malvern Instruments, Great Britain).

Moreover, rheological and sedimentation tests were performed on the suspension with and without several selected dispersants, that were tested in different proportions in order to stabilise the suspension to prevent agglomeration and sedimentation. Based on previous research on the dispersion of non-aqueous, ceramic suspensions, the selected dispersants tested in this work were as follows [25]:

- A combination of monoesters and diesters with a carbon chain length of 15-25 units (Emphos PS21A, Witco Chemical, USA) referred as Pho.

- An anionic polymeric dispersant (Hypermer KD7, Croma, UK) referred as KD7.

- A triglyceride with three units of unsaturated fatty acid, specifically oleic acid (Glyceryl trioleate, Fluka, Germany) referred as Triol.

- A solution of a block copolymer of high molecular weight (Disperbyk 190, Byk, Germany) referred as D190.

The rheological study, performed at $298 \mathrm{~K}$ using a double-cone and plate system, was done using a rheometer (Haake RS50, Thermo Scientific, Germany). With this equipment the rate was controlled (CR) by loading the shear rate from 0 to $1000 \mathrm{~s}^{-1}$ in $5 \mathrm{~min}$, maintaining it at $1000 \mathrm{~s}^{-1}$ for $1 \mathrm{~min}$ and downloading it from 1000 to $0 \mathrm{~s}^{-1}$ in 5 min.

Sedimentation tests, to determine the stability of the suspensions [26], were carried out in a multiple light scattering equipment (TurbiScan Classic MA2000, Formulaction, France), which can measure the variation with time of the amount of light backscattered by the suspended solids and the percentage of light transmitted by the liquid along the glass cell that contains the suspension. As a result, a family of curves (each one 
corresponding to a measurement of time) is obtained, which represents the percentage of light backscattered or transmitted as a function of glass cell height. All sedimentation tests were performed for one hour, taking data every five minutes. Figure 1 shows an example of stability test. On the left of that figure, an empty glass cell (Figure 1a) and filled with suspension (Figure $1 \mathrm{~b}$ corresponds to the beginning of the test, Figure 1c after half an hour and Figure 1d after one hour) are shown. On the right, the theoretical curves obtained from the experiment are plotted. In figure $1 \mathrm{~b}$, the amount of light backscattered is the same along the entire cell; consequently the obtained curve displays a straight profile. Nevertheless, as the solids settle (Figures 1c and 1d), the amount of light backscattered becomes higher on cell bottom, leading to a curve with peaks and valleys as shown by the theoretical curves.
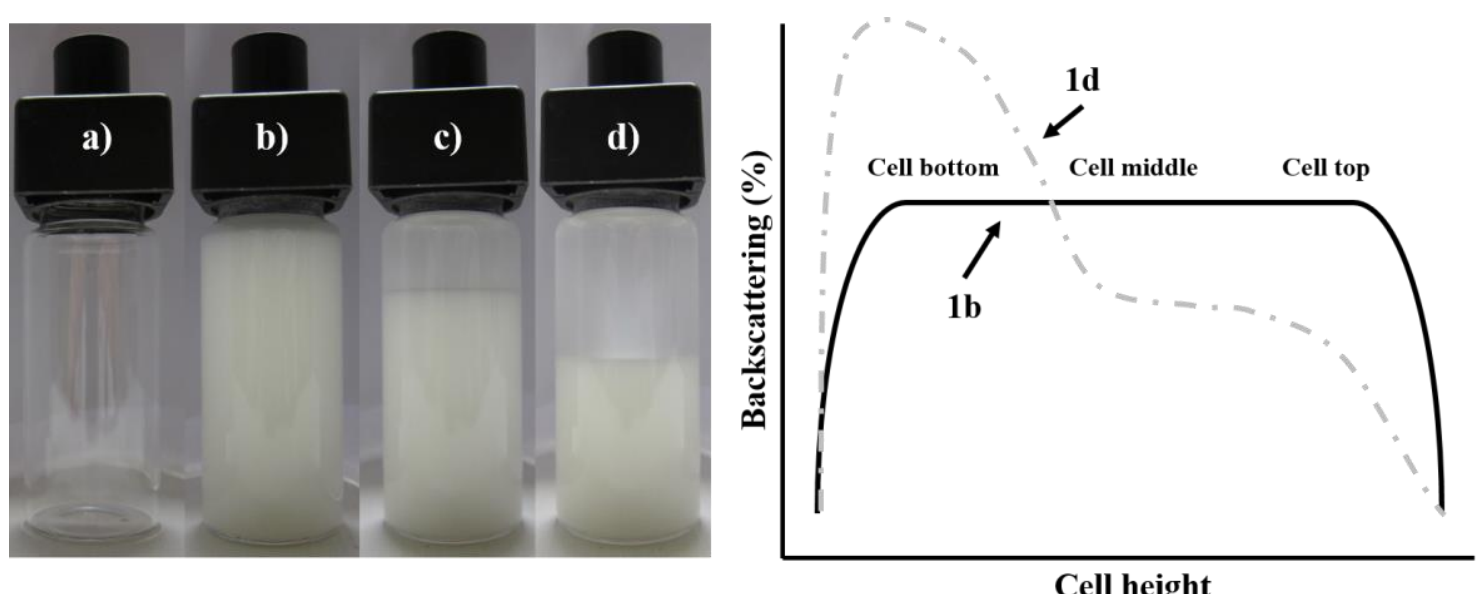

Figure 1 Left) Example of the glass cell employed in sedimentation tests. a: empty, b: full of suspension and ready for the test, c: with suspension after $0.5 \mathrm{~h}$ test and $\mathrm{d}$ : with suspension after $1 \mathrm{~h}$ test. Right) Theoretical sedimentation curves plotting the corresponding backscattering for pictures $1 \mathrm{~b}$ ) and $1 \mathrm{~d}$ )

Then, the second wet milling step was performed on the BG-Pul suspension containing dispersant in order to reach finer particle size. The nature and amount of the dispersant used were chosen depending on the obtained results once the rheological studies and the sedimentation tests were finished. The milling was carried out with an attrition mill (Dispermat SL, VMA-Getzmann GmbH, Germany) containing very small grinding alumina balls of $0.8 \mathrm{~mm}$ mean size. A milling mixture of 10 vol.\% solids and 90 vol.\% Dowanol DPM was used. The obtained suspension (referred as BG-Att) was characterised in the same way as the previous BG-Pul suspension (density, particle size distribution, rheological and sedimentation tests). Previously to characterisation, the optimum milling time was also determined. Nevertheless, this time cannot be assessed 
by sedimentation (as in the first milling step) since no distinction is possible between a turbid zone and a clear area due to the fine particle size of the ground suspension. Hence, particle size distribution was measured by laser diffraction for each milling time. Finally, particles morphology of the solid material in both suspensions was assessed by FEG-ESEM (QUANTA 200FEG, FEI Company, USA).

\subsection{Deposition and characterisation of the coatings}

Both types of suspensions (BG-Pul and BG-Att) were sprayed on metallic substrates by suspension plasma spraying (SPS). Coatings were deposited with a plasma torch (F4MB, Sulzer Metco, Switzerland) managed by a six axes robot (IRB 1400, ABB, Switzerland) employing argon as primary plasma gas and hydrogen as secondary plasma gas. The substrates, which were made of AISI type 304 stainless steel, had disc shape with a diameter of $25 \mathrm{~mm}$. Prior to coatings deposition, substrates were gritblasted using black corundum with a pressure of 4.2 $\mathrm{Pa}$ and were cleaned with ethanol, being the obtained roughness $\left(\mathrm{R}_{\mathrm{a}}\right) 2.2 \pm 0.1 \mu \mathrm{m}$. This value was determined employing a roughness tester (HOMMELWERKE T8000, Hommelwerke GmbH, Germany). A $\mathrm{TiO}_{2}$ powder was deposited by atmospheric plasma spraying (APS) from commercial anatase feedstock (Metco 102, Sulzer Metco, Switzerland), with particle size distribution between 10-55 $\mu \mathrm{m}$, as bond coat to enhance coatings adhesion such as reported by literature [22,27]. Moreover, the substrates were preheated between $300{ }^{\circ} \mathrm{C}$ and $350{ }^{\circ} \mathrm{C}$ to increase the adhesion too [28].

To deposit both suspensions, an injection system developed by the Instituto de Tecnología Cerámica (ITC) was coupled to the plasma torch [29]. The system is made up of two pressurised containers, which force the liquid to flow through an injector due to the pressure difference. A filter was placed into the injector to remove large agglomerates and possible contaminations that can clog the injector. The spraying conditions, based on literature data as well as on some previous research by the authors $[21,30]$, are detailed in table $2\left(\mathrm{TiO}_{2}\right.$ spraying parameters were given by the supplier). The spraying conditions were the same for both suspensions except the diameter of the injector, which was changed depending on the particle size distribution of the solid fraction in each suspension. Consequently, the suspension flow rates were different too. It should be noticed that these spraying conditions were not optimised since the optimising process was out of the scope of this paper. 
Table 2 Plasma spray conditions used for each type of suspension feedstock as well as for the $\mathrm{TiO}_{2}$ powder bond coat

\begin{tabular}{|c|c|c|c|}
\hline Parameter & $\begin{array}{c}\mathrm{TiO}_{2} \text { bond } \\
\text { coat (Powder) }\end{array}$ & $\begin{array}{c}\text { BG-Pul } \\
\text { (Suspension) }\end{array}$ & $\begin{array}{c}\text { BG-Att } \\
\text { (Suspension) }\end{array}$ \\
\hline Ar (slpm*) & 38 & 37 & 37 \\
\hline $\mathbf{H}_{2}\left(\mathbf{s l p m}^{*}\right)$ & 14 & 8 & 8 \\
\hline I (A) & 600 & 700 & 700 \\
\hline Spraying distance (m) & 0.12 & 0.08 & 0.08 \\
\hline Spraying velocity $\left(\mathrm{m} \mathrm{s}^{-1}\right)$ & 1 & 1.25 & 1.25 \\
\hline Nozzle diameter $(\mathbf{m}) \cdot 10^{3}$ & 1.80 & - & - \\
\hline Powder flow rate $\left(\mathrm{kg} \mathrm{s}^{-1}\right) \cdot 10^{4}$ & 7.50 & - & - \\
\hline Injector diameter $(\mathbf{m}) \cdot \mathbf{1 0}^{3}$ & - & 0.25 & 0.20 \\
\hline Suspension flow rate $\left(\mathrm{m}^{3} \mathrm{~s}^{-1}\right) \cdot 10^{6}$ & - & 1.48 & 0.32 \\
\hline
\end{tabular}

* Standard litre per minute

The amorphous/crystalline feature of the obtained coatings was assessed by XRD using a diffractometer (Advance diffractometer, Bruker Theta-Theta, Germany) and their microstructure was observed by FEG-ESEM.

\section{Results and discussion}

\subsection{First wet milling step (planetary mill)}

Figure 2 plots the results of sedimentation tests for the different milling times performed, measured as volume of suspended solids in a test tube, in order to determine the optimum milling time for this step. 


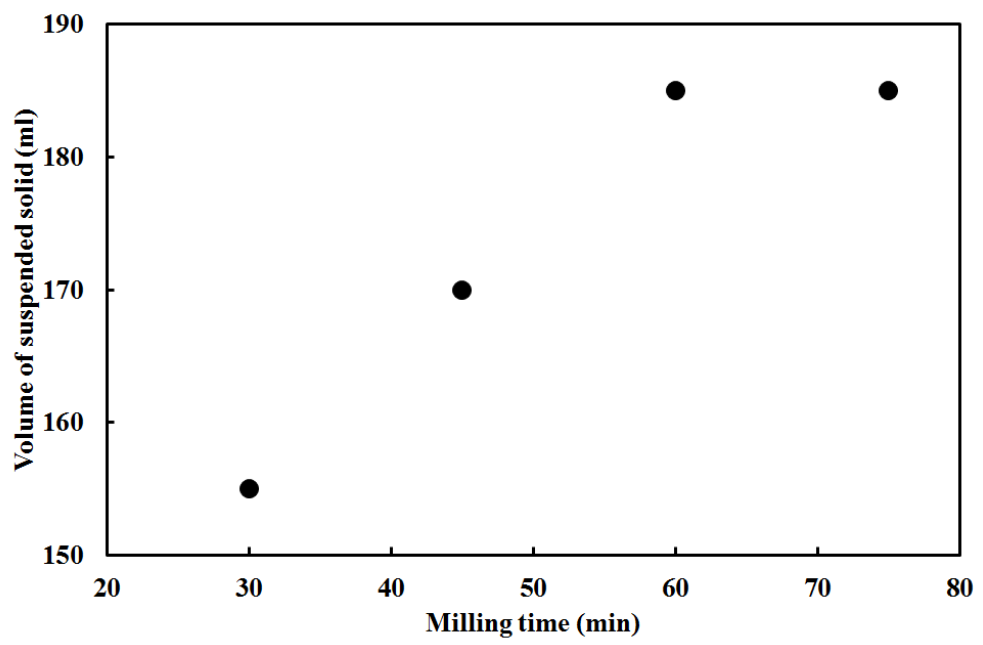

Figure 2 Variation of the suspended solids volume in sedimentation tests for different milling times (first milling step)

As expected particle size decreases with the increment of milling time, resulting in a slower sedimentation rate and higher volume of suspended solids as a consequence of particle build-up in the suspension. Besides, after one milling hour the volume of suspended solids remains constant, thus finer particle size cannot be reached with this milling step. Therefore, this time is considered as the optimum time.

The particle size distribution of the obtained suspension after one hour milling is plotted in figure 3 (continuous and dotted black curves for cumulative and frequency distributions respectively). In addition, particles morphology is shown in figure 4a.

A wide monomodal particle size distribution was obtained with $\mathrm{D}_{10}=2.0 \pm 0.3 \mu \mathrm{m}$, $\mathrm{D}_{50}=8.3 \pm 0.6 \mu \mathrm{m}$ and $\mathrm{D}_{90}=26.5 \pm 0.8 \mu \mathrm{m}$. This is a typical particle size distribution obtained in a planetary, laboratory ball mill. The width and average particle size of the distribution can also be observed in the SEM pictures of figure $4 \mathrm{a}$, where particles of different sizes are shown, being coarse particles $(>10 \mu \mathrm{m})$ quite predominant. In addition, all particles display the typical angular shape morphology of ground glass particles. 


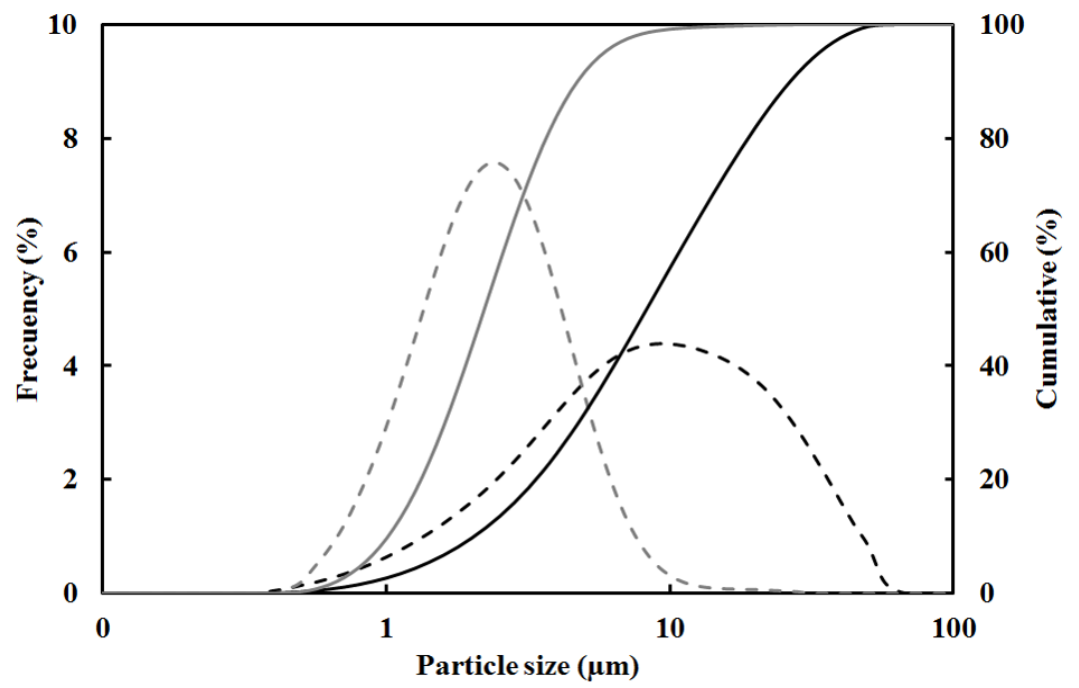

Figure 3 Particle size distributions for both types of suspensions. Continuous and dotted curves correspond to cumulative and frequency distributions respectively for BG-Pul suspension after one hour milling (black) and BG-Att suspension after 3 hours milling (grey)

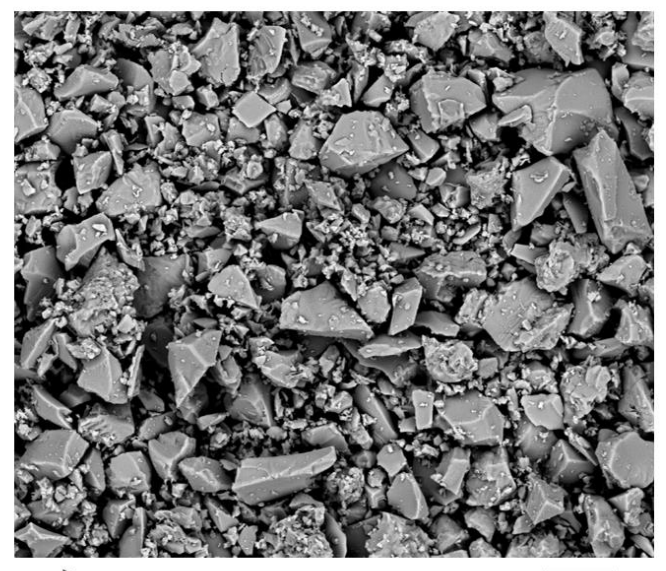

a) $\overline{10 \mu \mathrm{m}}$

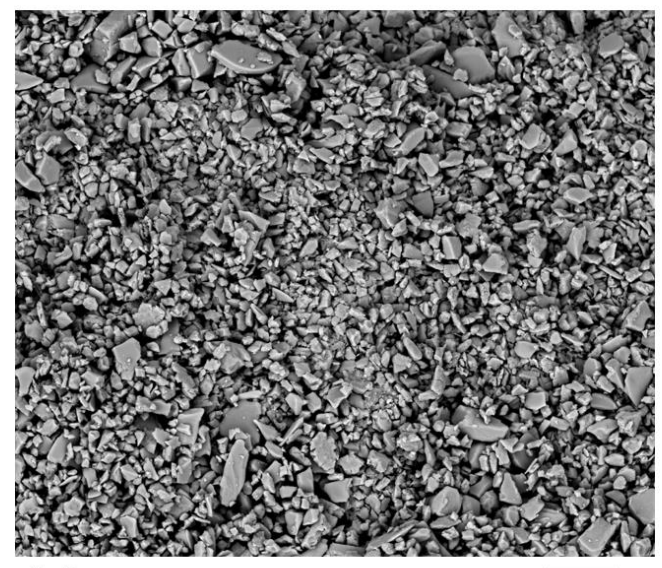

b)

$10 \mu \mathrm{m}$

Figure 4 Particles morphology obtained after drying both suspensions. Figure 4a: BG-Pul suspension (first milling step). Figure 4b: BG-Att suspension (second milling step)

Finally, density of the resulting suspension was also determined, being $1075 \mathrm{~kg} \mathrm{~m}^{-3}$. Concerning the stability of the BG-Pul suspension, the results obtained for the rheological tests are plotted in figure 5 as flow curve, which represent the shear stress as a function of the shear rate. This type of graph allows assessing the suspensions rheological behaviour in terms of viscosity, defined as the slope of the obtained curves, and the time dependence of flow behaviour (being thixotropy the most common case), which can also be obtained from this flow curve as the area closed between the uploading and downloading steps of the measurement [31]. 
In addition, table 3 sets out the values of thixotropy and viscosity measured at $900 \mathrm{~s}^{-1}$ shear rate in uploading step, of suspensions plotted in this figure.

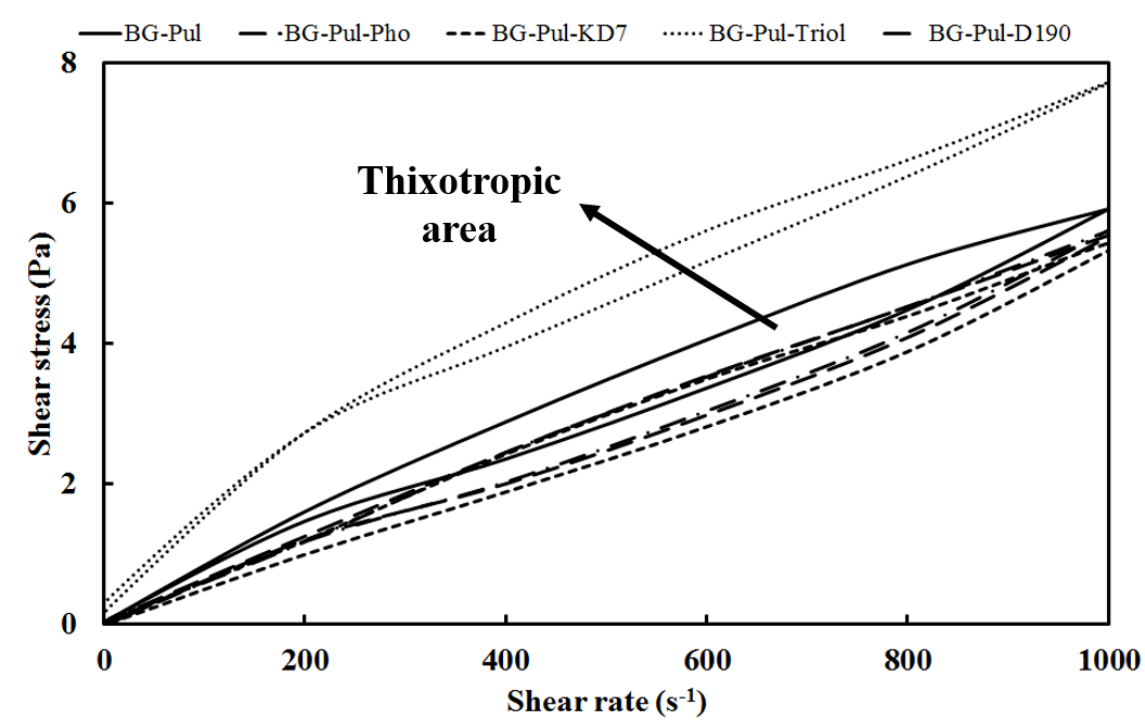

Figure 5 Flow curve for the BG-Pul suspension, with and without $0.5 \mathrm{wt} \%$ of the four tested dispersants, showing the thixotropic area

Table 3 Values of thixotropy and viscosity (measured at $900 \mathrm{~s}^{-1}$ shear rate in uploading step) of the BG-Pul suspensions with and without deflocculants, represented in figure 5

\begin{tabular}{lcc}
\hline Suspension & Thixotropic cycle $\left(\right.$ Pa s $\left.^{\mathbf{- 1}}\right)$ & ${\text { Viscosity }(P a ~ s) \cdot \mathbf{1 0}^{\mathbf{3}}}$ \\
\hline BG-Pul & 373 & 6.0 \\
BG-Pul-Pho & 277 & 5.5 \\
BG-Pul-KD7 & 369 & 5.4 \\
BG-Pul-Triol & 193 & 7.9 \\
BG-Pul-D190 & 231 & 5.5 \\
\hline
\end{tabular}

It can be observed that, after the first milling step, the obtained suspension shows a pseudoplastic behaviour with a viscosity value of approximately $6 \cdot 10^{-3} \mathrm{~Pa} \mathrm{~s}$ (measured at $900 \mathrm{~s}^{-1}$ shear rate in uploading step) as well as a visible thixotropic cycle of 373 $\mathrm{Pa} \mathrm{s}^{-1}$. This high thixotropy was consequence of the flocculated (structured) state of the suspension. This undesirable behaviour was tried to be changed by preparing mixtures of BG-Pul suspension with $0.5 \mathrm{wt} \%$ (\% relative to solids content) of different (four) dispersing agents as set out in section 2.1. The flow curves obtained are also shown in figure 5. Higher amounts of dispersant were not used due to the difficulty, in some cases, of preparing homogeneous mixtures. 
These flow curves demonstrate that the suspension maintains the pseudoplastic behaviour with the four different dispersant agents tested, but only Pho, KD7 and D190 dispersants reduced both viscosity and thixotropy, being this reduction minimal with regard to the suspension without dispersant (Table 3). Concerning the suspension in which Triol dispersant was used a significant reduction of thixotropic cycle takes place, however, the viscosity increases with respect to the BG-Pul suspension (Figure 5 and Table 3). Since Triol is a non-ionic surfactant, it seems that the presence of charges is necessary to promote the required electrostatic repulsion to maintain stability and to overcome the strong tendency to settle.

In brief, it can be stated that the addition of the non-ionic deflocculant (Triol) to the BGPul suspension does not provide the desired stability, since an increment of suspension viscosity takes place. A priori, only the addition of the ionic deflocculants (Pho, KD7 and D190) seem to do it (reduction of suspensions thixotropy and viscosity), but the reduction in viscosity is too low $\left(0.6 \cdot 10^{-3} \mathrm{~Pa} \mathrm{~s}\right.$, as observed in table 3$)$ to detect significant differences between suspensions containing these dispersants, and to determine the optimum dispersant agent which can stabilise the suspension. In addition, the tendency to settle is too high with all dispersant agents to preserve stability with time, so that sedimentation studies are necessary to determine the best dispersing conditions in terms of time stability [19].

Figure 6 represents the results of sedimentation tests for the BG-Pul suspension. This kind of plot shows the amount of light backscattered by the suspension into the cell as a function of time. At the beginning of the test (continuous black curve from Figure 6a) the amount of light backscattered is the same in the three zones of the vessel since the material has not begun to settle. For stable suspensions, those values of backscattered light should not change with time (the initial curve should remain unchanged). On the contrary, when the suspension is not stable, particles settle during the test, and the amount of backscattered light increases at the bottom and in the middle (depending on the sedimentation rate) of the cell, but decreases at the top. This phenomenon is illustrated in figure $6 \mathrm{a}$, for the curves plotted in function of the sedimentation time, as a deformation of the initial curve leading to a peak or flat profile in the area corresponding to the cell bottom while this profile progressively branches for the rest of the cell (continuous grey curve from Figure 6a). Therefore, from the analysis of the figure corresponding to the BG-Pul suspension, it can be deduced that this suspension is highly unstable, since the solid material rapidly settles with time. 

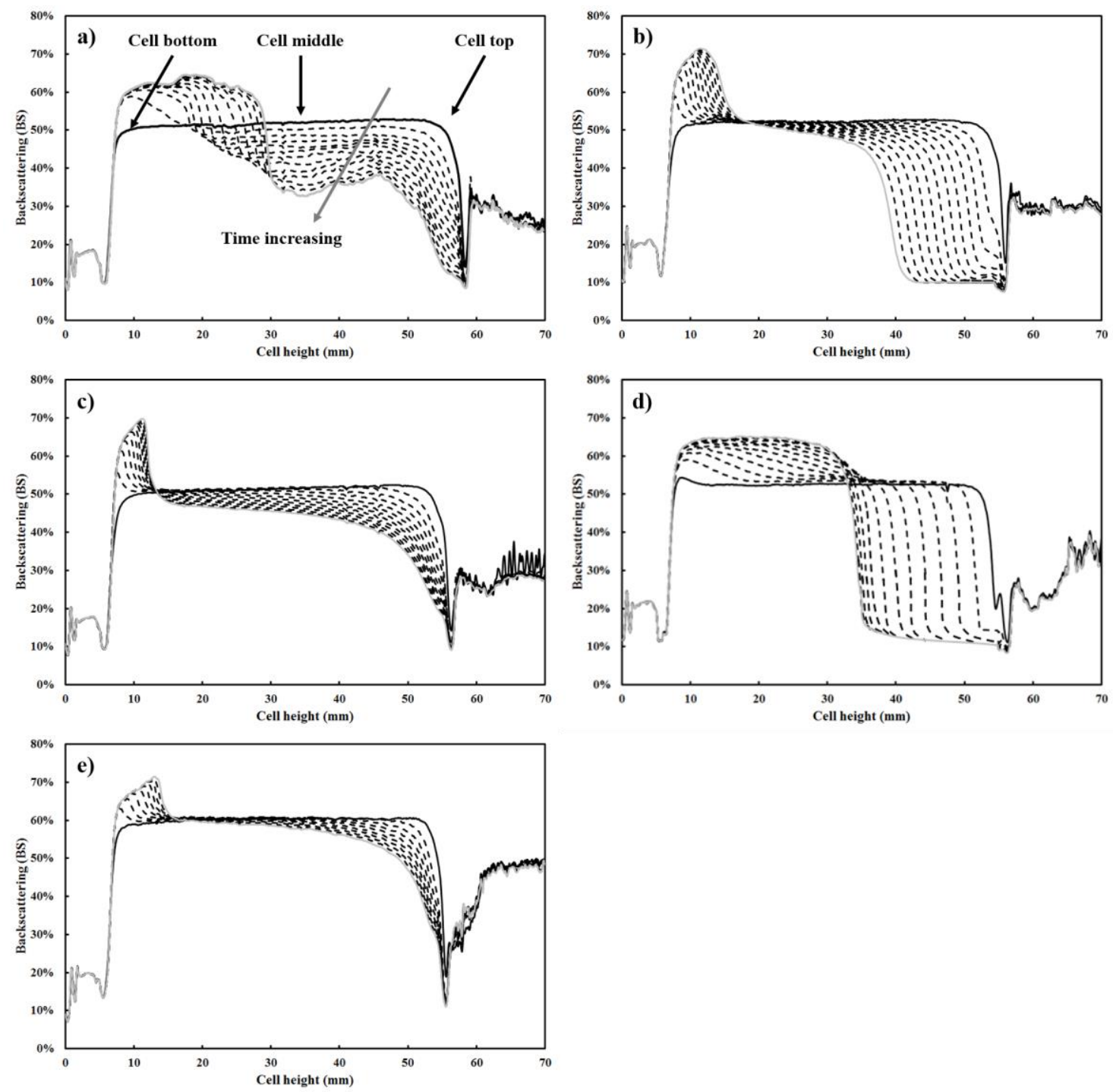

Figure 6 Results of the sedimentation test for the BG-Pul suspension without and with dispersant agents. Each curve from top to bottom represents the sedimentation profile monitored every five minutes during the sedimentation test until one hour. a) Without, b) Pho, c) KD7, d) Triol, e) D190

The high sedimentation tendency of BG-Pul sample (Figure 6a) is a consequence of a low viscosity but highly structured (flocculated) suspension as set out above.

Nevertheless, the addition of these four dispersants gave rise to dramatic changes in the evolution of the sedimentation curve profile. From the above figure, it can be stated that KD7 (Figure 6c) and D190 (Figure 6e) dispersants improved suspension stability, since the values of the backscattered light with time increased in the middle and the top of the cell. Moreover, the stability increment is much more significant for D190 sample. On contrary, dispersant Pho (Figure 6b) slightly retards the sedimentation with respect to the suspension without deflocculant (Figure 6a), and Triol sample (Figure 6d) does not 
improve stabilisation and cannot impede the fast sedimentation of the suspended solids. This behaviour can be observed in figure $6 \mathrm{~d}$ as the appearance of a flat curve at the zone corresponding to cell bottom, accompanied with a sharp drop of the backscattered light values from the cell top zone. With these tests the best dispersing conditions can be established in terms of sedimentation rate as no significant differences were found in the flow curves as repoted above.

Consequently, taking into account the results obtained from the sedimentation tests, D190 was chosen as the optimum dispersant agent, as this additive reduces suspension viscosity and thixotropy as well as sedimentation tendency, giving rise to a stable suspension which can be used as SPS feedstock $[18,19]$. However the particle size of the suspended solids $\left(\mathrm{D}_{50}=8.3 \pm 0.6 \mu \mathrm{m}\right)$ can make it difficult the feeding of the suspension through the injection nozzle into the plasma torch. For this reason, a second milling step was addressed.

\subsection{Second wet milling step}

As mentioned above a second wet milling step was implemented by grinding the BGPul-D190 suspension in an attrition mill. The obtained suspension was referred as BGAtt-D190. Figure 7 plots the evolution of the characteristic particle diameters of the solids in suspension determined by laser diffraction as a function of milling time.

It can be observed that fine particles $\left(\mathrm{D}_{10}\right)$ hardly changed their size, while medium sizes $\left(\mathrm{D}_{50}\right)$, reduced their initial size by factor 4 and coarse particles $\left(\mathrm{D}_{90}\right)$ by factor 6 . In addition, this figure shows that after three hours of milling, the size of the particles hardly varies, hence this time was chosen as the optimum grinding time for the second milling step.

The particle size distribution of the obtained suspension (BG-Att-D190) after three hours milling is plotted in figure 3 (continuous and dotted grey curves) and the particles morphology are shown in figure $4 \mathrm{~b}$. In addition, density was also determined being $1078 \mathrm{~kg} \mathrm{~m}^{-3}$, very close to that of the BG-Pul suspension as expected. 


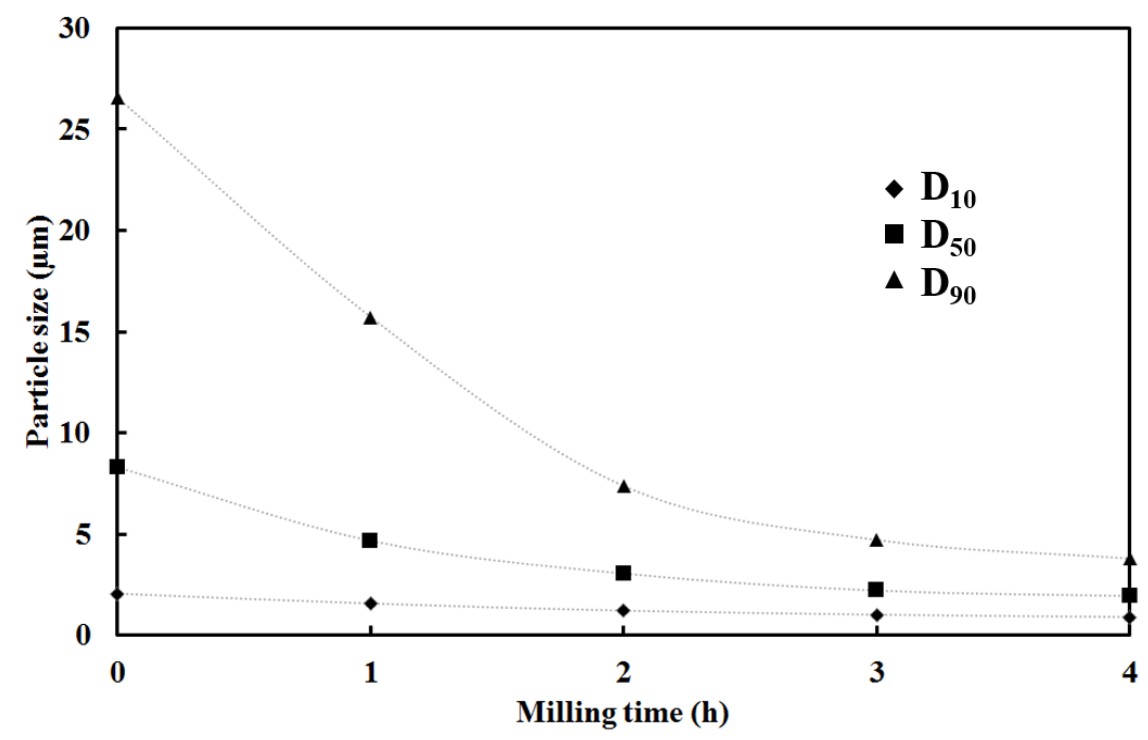

Figure 7 Particle size distributions of the BG-Att-D190 suspension in function of the milling time (three characteristic particle sizes of the distribution curve are shown)

Characteristic particle diameters of the BG-Att-D190 suspension after three hours milling (Figure 3) are: $\mathrm{D}_{10}=1.0 \pm 0.1 \mu \mathrm{m}, \mathrm{D}_{50}=2.2 \pm 0.1 \mu \mathrm{m}$ and $\mathrm{D}_{90}=4.7 \pm 0.2 \mu \mathrm{m}$. It can be shown that the particle size distribution remains monomodal, but a narrowing effect occurs when compared with the BG-Pul distribution (Figure 3). In addition, particle size of the new suspension was significantly reduced. In reference to the morphology of the particles (figure 4b) all of them also display the typical angular shape of ground glass particles. As evidenced by this figure, after the second milling step particles were finer and quite similar in shape.

To evaluate the effect of the second milling step on the stability of the BG-Att-D190 suspension, the flow curve of this suspension was determined, and plotted with the curve corresponding to the BG-Pul-D190 suspension as shown in figure 8. As it can be seen, this new suspension displays a pseudoplastic behaviour similar to that of the BGPul-D190 sample. Viscosity value (determined at $900 \mathrm{~s}^{-1}$ shear rate in uploading step) and thixotropy area were approximately $5.4 \cdot 10^{-3} \mathrm{~Pa} \mathrm{~s}$ and $219 \mathrm{~Pa} \mathrm{~s}^{-1}$ respectively. When compared with the data of the equivalent suspension (BG-Pul-D190) ground in the first milling step (Table 3), it can be stated that the dispersing efficiency of D190 additive is maintained through the second high-energy milling step. Nevertheless, the viscosity values are still too low to observe significant differences between both suspensions. Consequently, as in the first milling step, sedimentation tests are necessary to check the stability of the BG-Att-D190 suspension. The obtained results are shown in figure 9. In 
this figure, two sedimentation tests are shown, one test lasted one hour (Figure 9a) and the other one lasted 24 hours (Figure 9b).

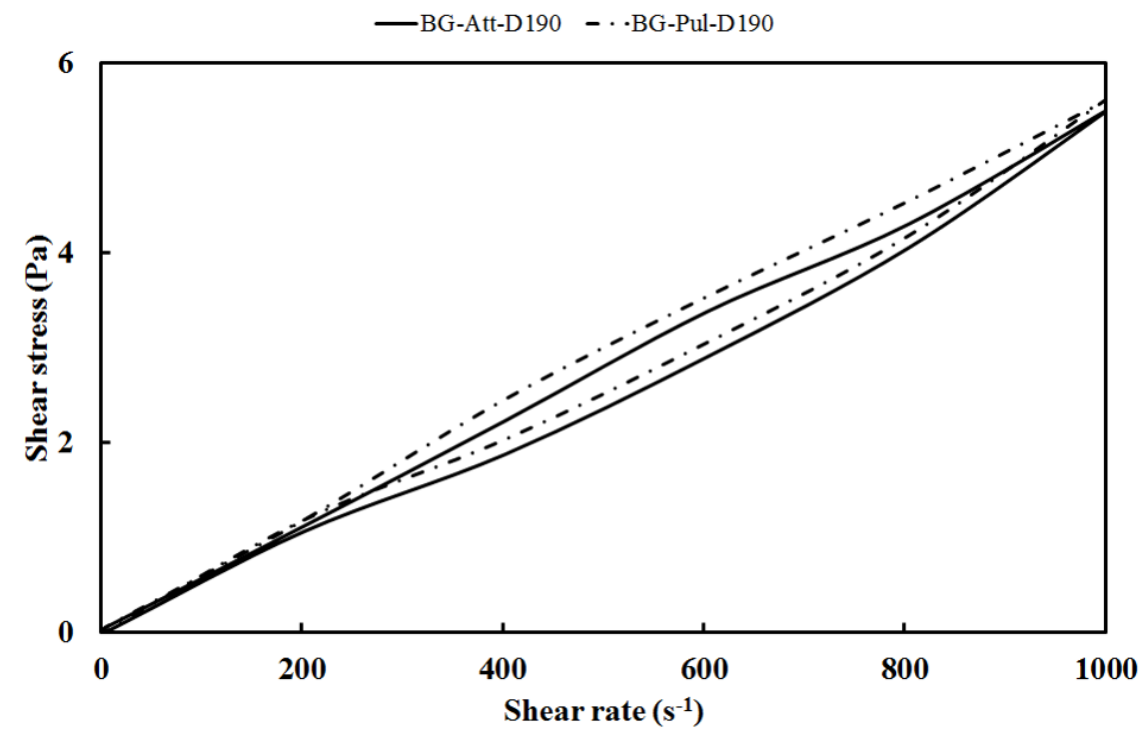

Figure 8 Flow curve for the BG-Att-D190 and BG-Pul-D190 suspensions

As it could be expected, the presence of the dispersant agent influences the stability of the suspension as shown in figure 9a. Thus, after one hour practically no sedimentation occurs as deduced by the curves profile in this figure. However, sedimentation still occurs for longer times as it is demonstrated in figure $9 \mathrm{~b}$ ( 24 hours test, taking measures every three hours) as the drop of the backscattered light values from the cell top zone after three hours test.
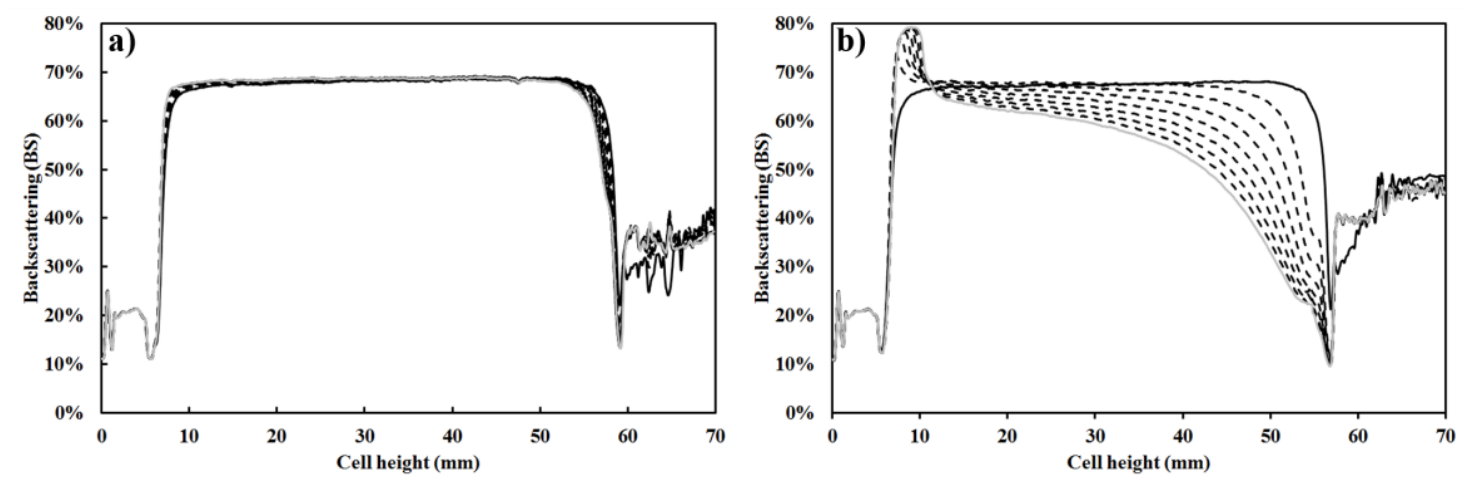

Figure 9 Results for the sedimentation test performed to the BG-Att-D190 suspension. a) After one hour, b) after 24 hours

As a summary, the dispersant effect of D190 remains after the second milling step and it can be stated that although solids sedimentation takes place with time, the BG-Att-D190 
suspension is quite stable (until 1 hour). As the suspension is easily redispersable, for longer periods of time, it would be enough to agitate the solids settled (zone of the curve shown in figure $9 \mathrm{~b}$ comprised between 5 and $12 \mathrm{~mm}$ of cell height) to disperse again the particles and to obtain a stable suspension for another hour.

\subsection{Coatings deposition and characterisation}

Suspensions obtained from each milling step were used as SPS feedstock. Both suspensions (BG-Pul and BG-Att) contained the dispersant D190 due to the positive effect shown by this additive, which managed to produce stable suspensions with an absence of sedimentation over one hour period, as shown in figures 6e and 9a. This time of stability was considered sufficient for the SPS process. In fact, the estimated time that the suspension stays in the SPS container and circuit for a real sample (not just a 25 mm disk) could be kept approximately lower than 1 hour, in function of type and dimensions of the sample (screw of a dental implant, hip prosthesis, etc). In these cases, the redispersion of the suspension by simple agitation would be the procedure to be followed as explained above.

The next step was the SPS deposition, which took place following the conditions described in table 2, to prove that it is possible to obtain coatings from these suspensions (preliminary coatings). As mentioned above, a $\mathrm{TiO}_{2}$ bond coat previously deposited by APS from powder feedstock was also used. When BG-Pul-D190 suspension feedstock was used (regardless of the presence of bond coat), no coating was obtained due to nozzle clogging caused by the presence of coarse glass particles and most probably by the formation of large agglomerates of finer particles. Thus, coatings were only obtained when the high-energy milled suspension (BG-Att-D190) was employed without or with a previous APS $\mathrm{TiO}_{2}$ bond layer, being preliminary coatings as mentioned above. Figure 15 displays the FEG-ESEM micrographs (section and surface) of the two coatings obtained from BG-Att-D190 suspension without and with the bond coat.

The coating showed in figure 15a (without bond coat), exhibits the typical cracked and porous microstructure of a glass coating [21]. Nevertheless, as it can be seen, its thickness is very thin $\left(20 \mu \mathrm{m}\right.$ approximately). When $\mathrm{TiO}_{2}$ bond coat was deposited before the glass layer, the obtained coating still shows the cracked and rounded porous microstructure of a glass coating, since the bond coat enhances coating adhesion but 
does not affect the coating microstructure [22,32]. However, the coating thickness significantly grows (60 $\mu \mathrm{m}$ approximately) with regard to the coating without bond coat $(20 \mu \mathrm{m})$. This unexpected finding can be due to the following causes: the spraying distance employed in coating deposition, the presence of a bond coat and the thermal conductivity values of the substrate (AISI304 stainless steel) and the bond coat $\left(\mathrm{TiO}_{2}\right)$. In both cases (with and without bond coat), due to the long spraying distance, most of the glass particles, which become agglomerated after the evaporation of the solvent, are melted and partially re-solidified during their flying along the plasma torch, reaching the substrate with insufficient temperature to be attached to the substrate [23]. Moreover, in the case of the coating without bond coat (Figure 10a), these agglomerates do not stick to the substrate due to the poor adherence between the ceramic top layer and the metallic substrate. On the other case (coating with bond coat), although the agglomerates have also melted and re-solidified, the presence of the bond coat enhances the adhesion between the glass coating and the substrate. In addition, since $\mathrm{TiO}_{2}$ has a lower thermal conductivity than the substrate (AISI304 stainless steel), the heat was not released too quickly from the glass agglomerates when impacting, giving to a progressive heating of the system with each torch cycle and reaching a temperature higher than the glass transition temperature $\left(\mathrm{T}_{\mathrm{g}}=520^{\circ} \mathrm{C}\right)$. As a result, a viscous glass coating was formed, and therefore an increment of the deposition efficiency took place. At this point, all particles (including the re-solidified ones) can easily stick to the coating [21-23]. 

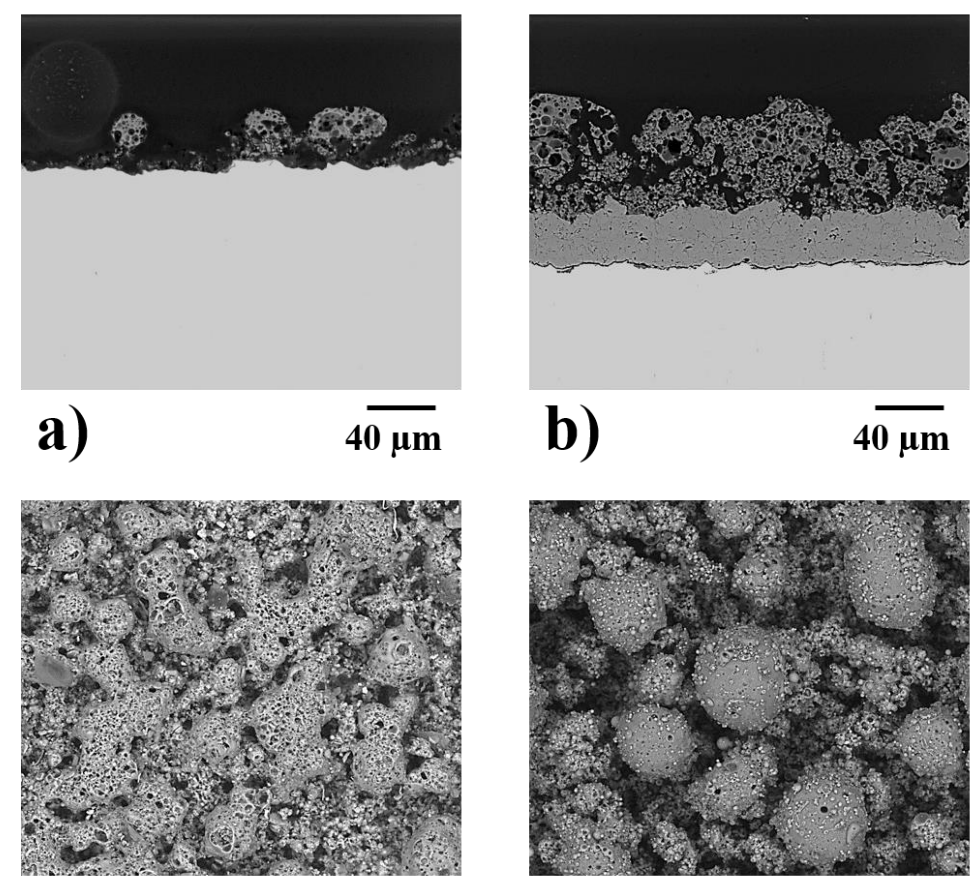

c)

$\overline{40 \mu m}$

d)

$40 \mu \mathrm{m}$

Figure 10 FEG-ESEM micrographs for coatings obtained with the BG-Att-D190 suspension. Figures 10a (surface) and 10c (section) without bond coat. Figures 10b (surface) and 10d (section) with bond coat

These differences between both coatings can also be observed in the SEM pictures of coating surfaces (Figures 10c and 10d). In the case of the coating without bond coat (Figure 10c), a slightly irregular surface $\left(\mathrm{R}_{\mathrm{a}}=10.9 \pm 0.5 \mu \mathrm{m}\right)$ was developed due to the faster release of heat when glass particles impact, their inefficient deformation and their lowest adherence to the substrate. In the bond coated sample (Figure 10d), the increment in the deposition efficiency is evident, since the surface is more irregular $\left(R_{a}\right.$ $=12 \pm 0.4 \mu \mathrm{m})$ than that of the other coating, with more material and plenty of large rounded glass agglomerates with a size of approximately tens of microns in diameter. However, this size is higher than that of the individual glass particles in the suspension. The formation of these coarse agglomerates is due to perturbations in the plasma torch, which reduce the perpendicular velocity component of the finest particles and increase the parallel velocity component of these particles before impacting onto the coating. As a consequence, the finest particles were deviated from their initial path and impact on the asperities (glass agglomerates) of the coating developed, forming a columnar structure namely the "cone shaped" structure [21,33], which is typical of some coatings obtained by SPS. As mentioned above, the coating keeps in a viscous state when these 
fine particles were deviated, therefore when they impact on the asperities, an increment of their size occurs.

Regardless the different contributions which can play a role in the development of these coatings, findings evidence that the spraying conditions must be optimised in order to produce coatings that maintain this roughness (good bioactivity) with adequate mechanical properties (low internal porosity) [23]. A research with this purpose is already in progress.

Finally, both coatings display an amorphous character, as demonstrated by the obtained XRD-patterns. Figure 11 shows the XRD-pattern, which corresponds to the BG-AttD190 coating with a bond layer (the other coating, without a bond coat, shows a similar XRD-pattern). This finding indicates that the amorphous character of the feedstock used in suspensions preparation, was preserved. Hence, it can be stated that no crystalline phases were developed, due to the high temperatures reached in the plasma plume, which melt any possible crystalline phase, as well as to the fast cooling of the splats when impacting on the substrate preventing coating devitrification. Amorphous nature in the glass coating is a necessary factor to optimise the glass coating bioactivity as reported elsewhere [14-16]. Simulated Body Fluid (SBF) tests to confirm the bioactivity index of the obtained coatings will be presented in the coming research.

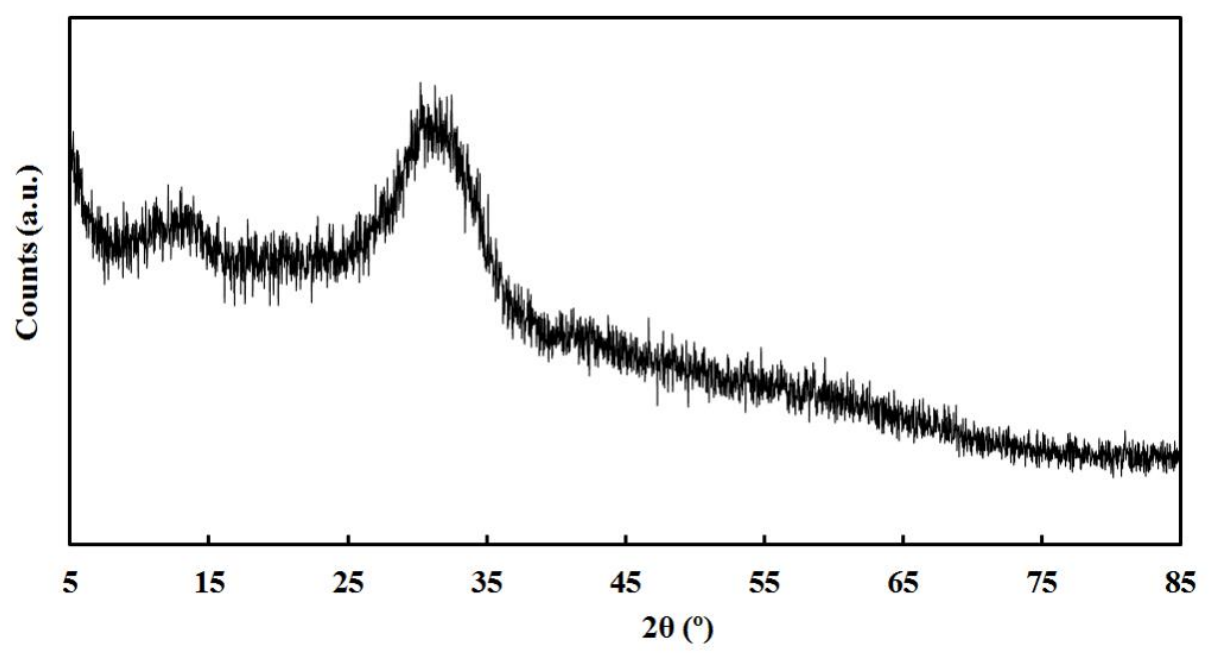

Figure 11 XRD pattern for BG-Att-D190 coating with $\mathrm{TiO}_{2}$ bond coat 


\section{Conclusions}

A bioactive glass powder, with amorphous character and micrometric particle size, was obtained from a frit. This powder was mixed with dipropylene glycol methyl ether as liquid solvent in order to develop a new type of feedstock for suspension plasma spraying. The mixture was wet milled in a planetary mill, obtaining a bioactive glass suspension (BG-Pul) with an average particle size of $\mathrm{D}_{50}=8.3 \pm 0.6 \mu \mathrm{m}$. Sedimentation of this suspension could be reduced by adding a dispersing agent. Nevertheless, this suspension feedstock could not be sprayed into the plasma torch owing to nozzle clogging produced by the large particle and agglomerate sizes contained in this suspension.

A second milling step was then performed, grinding the BG-Pul suspension containing a dispersant (0.5 wt\% of D190, \% relative to solids content) in an attrition mill, obtaining a suspension (BG-Att) with much finer particle size $\left(\mathrm{D}_{50}=2.2 \pm 0.1 \mu \mathrm{m}\right)$. The viscosity and thixotropic cycle of this suspension as well as the sedimentation rate become very low by means of this added, selected dispersant. Therefore, it can be stated that a stable suspension suitable for SPS process was obtained.

Thus, preliminary coatings were obtained with the BG-Att suspension (with and without bond layer). Microstructure was characterised by the presence of cracks and rounded pores. Nevertheless, when a $\mathrm{TiO}_{2}$ bond coat covered the substrate, coating's thickness was significantly increased respect to the coating without bond layer as a consequence of the increment of deposition efficiency due to the viscous state of the coating, as the bond coat prevents glass particles from fast heat release. However, the microstructure was not improved, thus their mechanical properties are expected to be poor. In addition, both coatings surfaces (with and without bond coat) were irregular and porous, in particular the surface of the coating with bond layer, which was made up of big rounded glass agglomerates forming the "cone shaped" structure. This structure gives rise to a high specific surface area which can be of interest for the enhancement of coating bioactivity.

The next milestone will be the deposition of bioactive coatings by SPS, with less internal porosity in order to enhance their mechanical properties, while maintaining or improving surface roughness to promote the reaction with biological fluids and surrounding tissues, reaching equilibrium between mechanical and biological properties. For that purpose, more research is in progress, regarding the optimisation of 
the spraying conditions in order to enhance particle melting and splat deformation, determining the adherence, hardness and bioactivity (SBF tests) of the new coatings in function of their microstructure features.

The results of this work allow us to conclude that the selected dispersing materials and conditions are adequate to prepare bioactive glass suspension feedstocks to be used in the development of bioactive coatings obtained by SPS process.

\section{Acknowledgements}

The authors of this study thank Universitat Jaume I of Castellon for the support provided in funding the project RECUBIO (P1-1B2013-69).

\section{References}

[1] G. Goller, H. Demirkiran, F.N. Oktar, E. Demirkessen, Processing and characterization of bioglass reinforced hydroxyapatite composites, Ceram. Inter. 29 (2003) 721-724.

[2] L. Lefebvre, J. Chevalier, L. Gremillard, R. Zenati, G. Thollet, D. BernacheAssolant, A. Govin, Structural transformations of bioactive glass 45S5 with thermal treatments, Acta Mater. 55 (2007) 3305-3313.

[3] M. Vallet-Regí, C.V. Ragel, A.J. Salinas, Glasses with medical applications, Eur. J. Inor. Chem. 2003 (2003) 1029-1042.

[4] J. Wilson, A. Yli-Urpo, R.P. Happonen, Bioactive glasses: Clinical applications, in: L.L. Hench, J. Wilson (eds.), An introduction to bioceramics, first edn., World Scientific, Singapore, 1993, pp. 63-74.

[5] T. Kokubo, Bioceramics and their clinical applications, first edn., CRC, The USA, 2008.

[6] J.R. Jones, Review of bioactive glass: From Hench to hybrids, Acta Biomater. 9 (2013) 4457-4486.

[7] S.J. Ding, Y.M. Su, C.P. Ju, J.H. Chern-Lin, Structure and immersion behaviour of plasma-sprayed apatite-matrix coatings, Biomater. 22 (2001) 833-845. 
[8] Y.W. Gu, K.A. Khor, P. Cheang, In vitro studies of plasma-sprayed hydroxyapatite/Ti-6Al-4V composite coatings in simulated body fluid (SBF), Biomater. 24 (2003) 1603-1611.

[9] V. Canillo, A. Sola, Different approaches to produce coatings with bioactive glasses: enamelling vs plasma spraying, J. Eur. Ceram. Soc. 30 (2010) 2031-2039.

[10] T.M. Lee, E. Chang, B.C. Wang, C.Y. Yang, Characteristics of plasma-sprayed bioactive glass coatings on Ti-6Al-4V alloy: an in vitro study, Surf. Coat. Technol. 79 (1996) 170-177.

[11] G.T. El-Bassyouni, H.H. Beherei, K.R. Mohamed, S.H. Kenawy, Fabrication and bioactivity behaviour of HA/bioactive glass composites in the presence of calcium hexaboride, Mater. Chem. Phys. 175 (2016) 92-99.

[12] P. Sepulveda, J.R. Jones, L.L. Hench, Characterization of melt-derived 45S5 and sol-gel-derived 58S bioactive glasses, J. Biomed. Mater. Res. (Appl. Biomater.) 58 (2001) 734-740.

[13] A. Lucas-Girot, F.Z. Mezahi, M. Mami, H. Oudadesse, A. Harabi, M. Le Floch, Sol-gel synthesis of a new composition of bioactive glass in the quaternary system $\mathrm{SiO}_{2}-\mathrm{CaO}-\mathrm{Na}_{2} \mathrm{O}-\mathrm{P}_{2} \mathrm{O}_{5}$ : Comparison with the melting method, J. NonCryst. Solids 357 (2011) 3322-3327.

[14] J.A. Juhasz, S.M. Best, Bioactive ceramics: processing, structures and properties, J. Mater. Sci. 47 (2012) 610-624.

[15] J.A. Helsen, J. Proost, J. Schrooten, G. Timmermans, E. Brauns, J. Vanderstraeten, Glasses and bioglasses: synthesis and coatings, J. Eur. Ceram. Soc. 17 (1997) 147-152.

[16] P.N. De Aza, A.H. De Aza, P. Pena, S. De Aza, Bioactive glasses and glassceramics, Bol. Soc. Esp. Ceram. Vidr. 46 (2007) 45-55.

[17] J.R. Davis, Handbook of thermal spraying technology, first edn., ASM International, The USA, 2004.

[18] L. Pawlowski, The Science and Engineering of Thermal Spray Coatings, second edn., John Wiley \& Sons, Great Britain, 2008. 
[19] R. Moreno, E. Bannier, Feedstocks suspensions and solutions, in: N. Espallargas (ed.), Future Development of Thermal Spray Coatings, Elsevier, Great Britain, 2015, pp. 51-80.

[20] S. Romeis, A. Hoppe, R. Detsch, A.R. Boccaccini, J. Schmidt, W. Peukert, Topdown processing of submicron 45S5 Bioglass ${ }^{\circledR}$ for enhanced in vitro bioactivity and biocompatibility, Proced. Eng. 102 (2015) 534-541.

[21] G. Bolelli, D. Bellucci, V. Cannillo, R. Gadow, A. Killinger, L. Lusvarghi, P. Müller, A. Sola, Comparison between Suspension Plasma Sprayed and High Velocity Suspension Flame Sprayed bioactive coatings, Surf. Coat. Technol. 280 (2015) 232-249.

[22] D. Bellucci, G. Bolelli, V. Cannillo, R. Gadow, A. Killinger, L. Lusvarghi, A. Sola, N. Stiegler, High velocity suspension flame sprayed (HVSFS) potassiumbased bioactive glass coatings with and without $\mathrm{TiO}_{2}$ bond coat, Surf. Coat. Technol. 206 (2012) 3857-3868.

[23] A. Cattini, L. Latka, D. Bellucci, G. Bolelli, A. Sola, L. Lusvarghi, L. Pawlowski, V. Cannillo, Suspension plasma sprayed bioactive glass coatings: Effects of processing on microstructure, mechanical properties and in-vitro behaviour, Surf. Coat. Technol. 220 (2013) 52-59.

[24] E. Cañas, M. Vicent, E. Bannier, P. Carpio, M.J. Orts, E. Sánchez, Effect of particle size on processing of bioactive glass powder for atmospheric plasma spraying, J. Eur. Ceram. Soc. 36 (2016) 837-845.

[25] R. Moreno, The role of slip additives in tape-casting technology. I: Solvents and dispersants, Am. Ceram. Soc. Bull. 71 (1992) 1521-1531.

[26] O. Mengual, G. Meunier, I. Cayré, K. Puech, P. Snabre, Turbiscan MA 2000: multiple light scattering measurement for concentrated emulsion and suspension instability analysis, Talanta 50 (1999) 445-456.

[27] A. Sola, D. Bellucci, V. Canillo, A. Cattini, Bioactive glass coatings: a review, Surf. Eng. 27 (2011) 560-572.

[28] P. Fauchais, Understanding plasma spraying, J. Phys. D. Appl. Phys. 37 (2004) 86-108. 
[29] M. Vicent, E. Bannier, P. Carpio, E. Rayón, R. Benavente, M.D. Salvador, E. Sánchez, Effect of the initial particle size distribution on the properties of suspension plasma sprayed $\mathrm{Al}_{2} \mathrm{O}_{3}-\mathrm{TiO}_{2}$ coatings, Surf. Coat. Technol. 268 (2015) 209-215.

[30] P. Carpio, E. Bannier, M.D. Salvador, A. Borrell, R. Moreno, E. Sánchez, Effect of particle size distribution of suspension feedstock on the microstructure and mechanical properties of suspension plasma spraying YSZ coatings, Surf. Coat. Technol. 268 (2015) 293-297.

[31] R. Moreno, Reología de Suspensiones Cerámicas (Ceramic Suspensions Rheology), first edn., CSIC, Spain, 2005.

[32] G. Goller, The effect of bond coat on mechanical properties of plasma sprayed bioglass-titanium coatings, Ceram. Inter. 30 (2004) 351-355.

[33] K. VanEvery, M.J.M. Krane, R.W. Trice, H. Wang, W. Porter, M. Besser, D. Sordelet, J. Ilavsky, J. Almer, Column formation in suspension plasma-sprayed coatings and resultant thermal properties, J. Therm. Spray Technol. 20 (2011) $817-828$. 